\title{
Maternal vitamin A status in intrauterine growth retarded babies
}

\author{
Alakh Ram Verma', Prafulla Kumar Khodiar², Debapriya Rath³, Seema Dhurandhar ${ }^{4}$, \\ Pradeep Kumar Patra ${ }^{5}$ \\ ${ }^{1}$ Associate Professor, Department of Physiology, ${ }^{2}$ Associate Professor, ${ }^{3}$ Assistant Professor, ${ }^{5}$ Director Professor, \\ Department of Biochemistry, ${ }^{4}$ Medical Officer, Pt. J.N. M. Medical College, Raipur, Chhattisgarh, India
}

\section{A B S T R A C T}

Background: Beside calorie and protein consumption micronutrients like folic acid, vitamin $D$ and vitamin $A$ have been postulated to play major role in intrauterine growth of neonates. Vitamin A compounds are critical for vision, reproduction, embryonic development, immune function and regulation of cell proliferation and differentiation. Aims and Objectives: To determine the relationship of maternal serum vitamin A levels with birth weight of babies. Material and Methods: Study group consisted of 58 randomly selected mothers who delivered at term small for gestational age babies (birth weight less than $2.5 \mathrm{~kg}$.). The control group comprises of 52 matched mothers, who delivered normal babies. Biochemical estimation of serum vitamin A was done by HPLC method using sigma reagent of all subjects. Results: Significantly high $(p<0.05)$ number of mothers in study group had low serum vitamin A level compared to mothers in control group. There was a linear relationship between vitamin A status and mean birth weight of the babies. Conclusion: Although the low serum vitamin A level of mothers was significantly associated with intrauterine growth retardation, the exact effect of a vitamin A deficiency on the birth weight of babies remain unclear, but the finding suggests the importance of adequate vitamin A supplementation to pregnant mothers in India.

Access this article online Website:

http://nepjol.info/index.php/AJMS DOI: 10.3126/ajms.v8i3.16862 E-ISSN: 2091-0576 P-ISSN: $2467-9100$

Key words: Vitamin A, Intrauterine growth retardation, Birth weight

\section{INTRODUCTION}

Low birth weight babies are neonates weighing less than $2500 \mathrm{gm}$ (WHO, 1984). ${ }^{1}$ They are of two groups, preterm(born before 37 weeks of gestation) and small for gestational age (intrauterine growth retardation). A weight below the $10^{\text {th }}$ percentile of expected weight for the population suggests intra uterine growth retardation (IUGR). ${ }^{1}$ Growth retardation is a major public health problem worldwide. WHO estimates that globally about 25 millions low birth weight babies (LBW) born each year, consisting $14 \%$ of all live birth, nearly $93 \%$ of them in developing countries. ${ }^{2}$ In India about $25-35 \%$ of babies are low birth weight and among them $60-70 \%$ are term IUGR and rests are preterm. Fetuses who suffer from growth retardation have higher peri-natal morbidity and mortality. During Childhood they are more likely to have poor cognitive development and neurological impairment. ${ }^{3}$

Amongst macronutrients protein and calorie consumption have been postulated to play a major role. Amongst micronutrients, iron, zinc, folic acid, vitamin $\mathrm{D}$, vitamin $\mathrm{A}$ and Magnesium are presumed to play an important role. ${ }^{4}$ The role of some of these (iron, zinc, folic acid, magnesium) has been confirmed by various studies, other nutrient supplementations are yet to establish a clear cut role in prevention of IUGR. ${ }^{5}$

Vitamin A compounds are fat soluble micronutrients that are critical for many functions, including vision, reproduction, embryonic development, growth, immune 
function, and regulation of cell proliferation and differentiation. Therefore, vitamin A is essential for successful gestation. ${ }^{6}$

Researchers have shown a very positive influence of vitamin A on plasma progesterone \& estrogen levels during pregnancy. Since progesterone is responsible for healthy feto-placental function, it is postulated that besides its confirmed role in cellular differentiation and morphogenesis, vitamin A may also have an indirect role in fetal growth and maturity.

Various studies have however revealed a very high prevalence of vitamin A deficiency in pregnant women. In many locations, the prevalence exceeds the current international vitamin A consultative group criteria for the definition of a problem of public health significance. Whether this deficiency translates into LBW \& IUGR or not is yet to be established. ${ }^{7}$

The present study was therefore performed to determine the level of vitamin A in mothers delivering at term small for gestational age (SGA) babies' vis-a-vis in mothers delivering at term appropriate for gestational age (AGA) babies. We also tried to determine whether maternal vitamin A deficiency had any causal relationship with IUGR or both were part of the same overall etiological syndrome resulting in simultaneous but unrelated occurrence of both the condition.

\section{MATERIALS AND METHODS}

The present study was conducted in the departments of Physiology, Biochemistry and Obstetrics and Gynaecology in Pt. J.N.M. Medical College, Raipur and associated

Dr. B.R. Ambedkar Memorial Hospital, Raipur (C.G.) from July 2015 to January 2016.

Approval from the ethics committee of the institution was obtained.

The Study group consisted of 58 randomly selected mothers who delivered at term (gestational age 37-42 weeks) small for gestational age (SGA) babies (Birth weight $<2.5 \mathrm{~kg}$ ).

The control group comprised of 52 randomly selected appropriately matched mothers who delivered at term (gestational age 37-42 weeks) appropriate for gestational age (AGA) babies (Birth weight $>2.5 \mathrm{~kg}$.)

For selection of cases, the pregnant women attending the labour room were screened for the study and were counseled for the purpose of interrogation and investigation and an informed consent was obtained.

Maternal built, height, weight to calculate BMI was measured and general as well as systemic examinations and routine investigation were done including as a part of routine anti natal care. ${ }^{8}$

Mothers suffering from ante-partum hemorrhage and insulin dependent diabetes mellitus and mothers of babies having congenital malformations, perinatal asphyxia, respiratory distress syndrome, and meconium aspiration were excluded from the study as these are well established determinants of IUGR.

For estimation of serum Vitamin 'A' all the subjects were sampled within 24 hours of delivery, $5 \mathrm{ml}$ venous blood was withdrawn from the mother. $2 \mathrm{ml}$ of blood was taken in tubes containing EDTA for estimation of Hemoglobin. From rest of blood serum was recovered by centrifugation within 2 hours \& stored at $-70^{\circ} \mathrm{C}$, until vitamin A estimation was done. Storage \& analysis were done avoiding direct exposure of light. Serum Vitamin A was estimated by high performance liquid chromatography (HPLC) using HPLC grade solvents and vitamin A standards of Sigma Aldritch chemicals. ${ }^{9}$

Interpretation of serum Vitamin A level is as below-

$\begin{array}{ll}\text { Level } & \mu \mathrm{g} \text { of vitamin } \mathrm{A} / 100 \mathrm{ml} \\ \text { High } & >50 \\ \text { Acceptable } & 20-49 \\ \text { Low } & 10-19 \\ \text { Deficient } & <10\end{array}$

Complete systemic examination of babies were done to rule out congenital anomaly and Apgar score, birth weight, length, gestational age, head circumference and chest circumference were recorded.

Data for each variable were obtained separately for mothers of SGA and AGA neonates and results were statistically analyzed using percentage, mean, standard deviation, student ' $t$ ' test, chi square test and regression analysis.

\section{RESULTS}

SGA babies were significantly higher in mothers with BMI $<18.5(\mathrm{p}<0.05)$. In study group 33\% mothers had BMI less than normal range $(<18.5)$ as compare to only $12.5 \%$ mothers in control group (Table 1). Mean BMI of study and control group was $19.711 \pm 2.17$ and $21.806 \pm 2.46$ respectively $\&$ the difference was highly significant $(\mathrm{P}<0.01)$. 


\begin{tabular}{|c|c|c|c|c|c|c|}
\hline \multirow[t]{2}{*}{ Body mass Index of subject } & \multicolumn{2}{|c|}{ Study group $(n=58)$} & \multicolumn{2}{|c|}{ Control $(n=52)$} & \multirow[t]{2}{*}{ Total } & \multirow[t]{2}{*}{ P Value } \\
\hline & No. & $\%$ & No. & $\%$ & & \\
\hline$<18.5$ & 20 & 35 & 7 & 12.5 & 19 & $<0.05$ \\
\hline $18.5-24.99$ & 36 & 62.5 & 40 & 77.5 & 56 & $>0.05$ \\
\hline$>25$ & 2 & 2.5 & 5 & 10 & 5 & $>0.05$ \\
\hline Total & 58 & 100 & 52 & 100 & 110 & \\
\hline Mean+/-SD & \multicolumn{2}{|c|}{$19.711+/-2.17$} & \multicolumn{2}{|c|}{$21.806+/-2.46$} & & $<0.01$ \\
\hline
\end{tabular}

\begin{tabular}{|c|c|c|c|c|c|c|c|c|c|c|c|}
\hline \multirow{4}{*}{$\begin{array}{l}\text { Maternal serum } \\
\text { vitamin A (mcg/dl) }\end{array}$} & \multicolumn{10}{|c|}{ Birth weight in kg } & \multirow[t]{4}{*}{ Total $(n=110$} \\
\hline & \multicolumn{4}{|c|}{ Term SGA babies } & \multicolumn{6}{|c|}{ Term AGA babies } & \\
\hline & \multicolumn{2}{|c|}{$1.5-2$} & \multicolumn{2}{|c|}{$2-2.5$} & \multicolumn{2}{|c|}{$2.5-3$} & \multicolumn{2}{|c|}{ 3-3.5 } & \multicolumn{2}{|c|}{$3.5-4$} & \\
\hline & No. & $\%$ & No. & $\%$ & No. & $\%$ & No. & $\%$ & No. & $\%$ & \\
\hline $10-19$ & 4 & 22.2 & 8 & 19.2 & 1 & 3.2 & 1 & 14.3 & 0 & 0 & 14 \\
\hline $20-30$ & 6 & 33.4 & 11 & 27 & 12 & 29 & 4 & 42.85 & 0 & 0 & 33 \\
\hline $30-40$ & 0 & 0 & 6 & 15.4 & 6 & 16.1 & 0 & 0 & 1 & 0 & 13 \\
\hline $40-50$ & 4 & 22.2 & 9 & 23 & 8 & 19.4 & 0 & 0 & 1 & 50 & 22 \\
\hline$>50$ & 4 & 22.2 & 6 & 15.4 & 13 & 32.3 & 4 & 42.85 & 1 & 50 & 28 \\
\hline Total & 18 & 100 & 40 & 100 & 40 & 100 & 9 & 100 & 3 & 100 & 110 \\
\hline $\begin{array}{l}\text { Mean+/-SD (Maternal } \\
\text { serum vitamin } A \text { ) }\end{array}$ & \multicolumn{2}{|c|}{$35.22+/-18.33$} & \multicolumn{2}{|c|}{$37.71+/-21.4$} & \multicolumn{2}{|c|}{$44.19+/-20.24$} & \multicolumn{2}{|c|}{$45+/-22.94$} & & & $P<0.05$ \\
\hline
\end{tabular}

Mean level of birth weight of babies both in terms SGA and AGA increased with increasing serum vitamin $A$ levels in mothers. But mothers of term SGA babies have significantly low serum vitamin A compared to mothers of term AGA babies $(p<0.05)$. This show a linear relationship between the birth weight of baby and serum vitamin A levels of mothers with term SGA babies. All the babies with birth weight more than $3.5 \mathrm{Kg}$. had normal serum vitamin A levels in mothers (Table 2 ).

\section{DISCUSSION}

\section{Magnitude of Low Birth Weight}

Low birth weight is one of the main predictors of infant mortality. The incidence of LBW varies widely between regions of world. World-wide, out of 139 million live births, about 23 million infants have low birth weight and 19 million of these babies were born in the developing countries. ${ }^{1}$

In India about $25-35 \%$ of babies are LBW as compared to $5-7 \%$ of newborn of the developed countries. 6-8 million LBW infants are born annually in India out of which $60-70 \%$ are term IUGR and rest pre-term. Thus roughly $2 / 3^{\text {rd }}$ of LBW in our country are small for date and nearly $1 / 3^{\text {rd }}$ of Indian neonates are pre-term LBW weighing $<2500$ gm at birth. ${ }^{2}$ Reported incidence of LBW babies in some countries is shown in Table 3.

\section{Causes of Low Birth Weight}

The causes of LBW have been the focus of a vast number of investigators over the last few decades and with the

\begin{tabular}{lc}
$\begin{array}{l}\text { Table 3: Reported incidence of LBW in some } \\
\text { developed and developing countries }\end{array}$ \\
\hline Country & $\%$ of live births \\
\hline India & 28 \\
Srilank & 22 \\
Thailand & 9 \\
China & 2 \\
Bangladesh & 22 \\
Pakistan & 19 \\
USA & 8 \\
Singapore & 8 \\
Sweden & 4 \\
UK & 8 \\
Switzerland & 6 \\
\hline UNICEF (2009), State of world's children 2009 &
\end{tabular}

general availability of fairly accurate weighing devices, birth weight and its determinants have come under intense global scrutiny. As a result, it is now acknowledged that many factors can influence length of gestation or rate of intrauterine growth, i.e. causality of LBW is 'multifactorial'. Nonetheless there is considerable confusion and controversy about the factors that have independent effect on LBW as well as the quantitative importance of those effects. $^{10}$

Maternal BMI (Body Mass Index) and Birth Weight of Babies

$\mathrm{BMI}=\mathrm{wt}(\mathrm{kg}) / \mathrm{ht} 2(\mathrm{~m})$

Since weight is known to increase with increase in age and parity, influence at weight or height on birth weight 
was analyzed as wt./ht2. reflects the nutritional status irrespective of age and parity. ${ }^{11}$

Mother with BMI $<18.5$ indicates chronic energy deficiency, between $18.5-24.99$ indicate normal, $>25$ indicate overweight and obesity.

In present study $35 \%$ mothers in study group had $\mathrm{BMI}<18.5 \mathrm{~kg} / \mathrm{m} 2$ as compared to only $12.5 \%$ mothers in control group $(p<0.05)$. It shows that maternal undernutrition is a significant risk factor for IUGR. If we compared mean BMI of mothers of study and control group, it was significantly less $(p<0.01)$ in study group as compared to control group.

Role of Vitamin A in Embryo-genesis, Growth and Development

Both vitamin $A$ excess and deficiency are known to cause birth defects. Vitamin A and retinoic acid (RA) are essential for embryonic development. During fetal development, RA functions in limb development and formation of the heart, eyes, and ears. Additionally, RA has been found to regulate expression of the gene for growth hormone. The growth and differentiation of epithelial cells throughout the body are especially affected by vitamin A deficiency. ${ }^{12,13}$

Panth et al studied the effect of vitamin A supplementation on plasma progesterone and estrogen levels during pregnancy and concluded that there was a significant increase in progesterone levels without any effect on estradiol levels. It is well known that progesterone is responsible for healthy fetoplacental function, also some study shows that vitamin A deficient mothers have morphological abnormality in their placentae, like reduced size and surface area of villi which could account for the reduced nutrient transport across to the fetus, poor placental function in the presence of vitamin A deficiency can cause IUGR..$^{14,15}$

Dabi et al also have described that vitamin A deficiency appears to be a key factor for IUGR in mothers who are otherwise nor severely malnourished. ${ }^{7}$

In the present study the distribution of serum vitamin A levels in the mothers shows 14 subjects had less than normal $(10-19 \mathrm{mcg} / \mathrm{dl})$ levels. Out of these 14 subjects only 02 were in control group i.e. with term AGA babies and rest 12 were in study group with term SGA babies.

\section{CONCLUSION}

In our study vitamin A deficiency was observed in pregnant women, and this is one of the very important factor associated with higher prevalence of growth restriction of the fetus and found in poorly nourished population. Although the low serum vitamin A level of mothers was significantly associated with IUGR, the exact effect of a vitamin A deficiency during pregnancy on the birth weight of babies remain unclear, but the finding suggests the importance of satisfactory vitamin A supply to pregnant mothers in Indian context where habitual diet are either inadequate or deficient in vitamin A, to prevent vitamin A.

Also there was a linear relationship found between maternal vitamin A status and mean birth weight of babies, but this was statistically not significant because of less no subjects in our study. Although we have adjusted a variety of confounding factor but in malnourished mothers, beside vitamin A many other factor also have an influence of intrauterine growth restriction. So a bigger study required with a large number of subject and after possible elimination of various confounding factors which can say beyond doubt that low maternal vitamin A status is important risk factor for intra uterine growth retardation.

\section{ACKNOWLEDGEMENT}

Department of Biochemistry, Pt JNM Medical College, Raipur (CG)

\section{REFERENCES}

1. World Health Organization: The Incidence of low birth weight: an update. Wkly epidemol Rec., 1984; 59:205-211.

2. Park K., Section 10, Preventive medicine in Obstetrics, Paediatrics and Geriatrics, Textbook of Preventive and Social Medicine $20^{\text {th }}$ Edition, Jabalpur, M/s. Banarsidas Bhanot, 2009, Page 460.

3. Singh Meharban, section 17, Disorder of weight and Gestation, Care of the Newborn; sixth Editon; p 219-235.

4. Williams RL, Creasy RK, Conningham GC, Hawe, WE, Norris FD and Tashiro M. Fetal growth and perinatal viability in California. Obs. and Gynecol 1982; 65: 663-737.

5. Sharma M, Kumar D, Huria A and Gupta P. Maternal Risk Factors Of Low Birth Weight In Chandigarh India. The Internet Journal of Health 2008;9(1).

6. Mary G. Enig. Vitamin A for fetal development (www. westonaprice.org/knowyourfats/vitamin-a-fetal.html).

7. Dabi DR, Manish $\mathrm{P}$ and Anuradha B. A study of maternal vitamin A status and its relationship with intrauterine growth restriction. J.Obstet Gynecol India 2006; 56(6): 489-494.

8. Ghosh S. Hooja V, Mittal SK, Verma RK, Ghosh S, Hooja V, et al. Biosocial determinants of birth weight.Indian Pediatr 1977;14:107-113.

9. Kramar MS. Determinants of low birth weight: Methodological assessment and meta analysis. Bull WHO 1987; 65: 663-737.

10. Underwood BA. Maternal vitamin A status and its importance in infancy and early childhood. Am J Clin Nutr 1994; 59(suppl): 517S-524S. 
11. Hirve SS and Ganatra BR, Determinants of Low Birth Weight: A Community Based Prospective Cohort Study. India Pediatr 1994, 31:1221-1225.

12. Ross AC and Gardner EM. The function of Vitamin A in cellular growth and differentiation and its roles during pregnancy \& lactation. Adv Exp Med Biol 1994;352:187-200.

13. Shah RS and Rajalaxmi R. Vitamin A status of the newborn in relation to gestational age, body weight, and maternal nutritional status. Am J Clin Nutr 1984; 40:794-800.

14. Biswas AB, Mitra NK, Chakraborty I, Basu S and Kumar S. Evaluation of vitamin A status during pregnancy. J. Indian Med Assoc 2000; 98(9): 525-529.

15. Panth $M$, Raman L, Ravindra $P$ and Sivakumar B. Effect of vitamin A supplementation on plasma progesterone and estradiol levels during pregnancy, Int $\mathrm{J}$ Vitm Nutr Res 1991:61(1):17-19.

\section{Authors Contribution:}

ARV - Concept and design of the study; PKK- Review of literature, preparation of first draft of the study and critical review of the manuscript;DR- Manuscript preparation and statistical analysis and interpretation; SD - Laboratory work, review of literature; PKP- Review of study, manuscript preparation.

Work attributed to:

Department of Physiology, Pt JNM Medical College, Raipur (CG)

Orcid ID:

Dr Alakh Ram Verma: (D) http://orcid.org/0000-0002-4913-6537

Dr Prafulla Kumar Khodiar: (1) http://orcid.org/0000-0002-9254-9396

Dr Debapriya Rath: (1) http://orcid.org/0000-0003-1908-2416

Dr Seema Dhurandhar: http://orcid.org/0000-0002-7748-765X

Dr Pradeep Kumar Patra: (i) http://orcid.org/0000-0003-4426-0384

Source of Support: None, Conflict of Interest: None declared. 